\title{
GAMBARAN DUKUNGAN ORGANISASI YANG DIRASAKAN PADA KARYAWAN PT. XYZ
}

\author{
FX. Yanuar Sidharta ${ }^{1}$ Zamralita $^{2}$ \\ ${ }^{1}$ Fakultas Psikologi, Universitas Tarumanagara Jakarta \\ Email: yanuar.717151025@stu.untar.ac.id \\ ${ }^{2}$ Fakultas Psikologi, Universitas Tarumanagara Jakarta \\ Email: zamralita@fpsi.untar.ac.id
}

\begin{abstract}
ABSTRAK
Karyawan merupakan aset yang tidak ternilai bagi suatu perusahaan. PT. XYZ merupakan perusahaan baru yang bergerak di bidang consumer goods dengan produk popok bayi dan pembalut wanita. Tiap karyawan memiliki andil yang penting untuk membangun citra positif perusahaan. Hal ini tentunya memerlukan persepsi yang positif dari karyawan terhadap perusahaan. Yang terjadi pada bagian logistik di PT. XYZ, masih memerlukan cara tertentu untuk membangun persepsi yang positif, terutama bagaimana harus menyadari akan bantuan fasilitas yang telah diberikan kepada karyawan dalam bekerja. Harapan dari perusahaan adalah semakin lama mereka bekerja, maka semakin dapat memahami kondisi perusahaannya, termasuk segala dukungan yang telah diberikan kepada mereka dalam bekerja, meski belum sempurna, mengingat usia perusahaan yang masih tergolong sangat muda. Persepsi karyawan terhadap bagaimana perusahaan menghargai kontribusi mereka dan peduli terhadap kesejahteraan mereka disebut sebagai dukungan organisasi yang dirasakan. Tujuan dari penelitian ini adalah untuk mendapatkan gambaran perceived organizational pada karyawan perusahaan. Metode yang digunakan penelitian ini metode kuantitatif. Responden penelitian adalah karyawan perusahaan yang berjumlah 153 orang, dengan rincian 67 orang laki-laki, 86 orang perempuan. Data penelitian diperoleh melalui kuesioner. Hasil dari penelitian ini diperoleh nilai rata-rata (Mean) perceived organizational support yakni 3.578, yang termasuk dalam kriteria sedang pada karyawan yang bekerja di perusahaan tersebut.
\end{abstract}

Kata kunci: Karyawan, Dukungan Organisasi Yang Dirasakan, Persepsi.

\section{PENDAHULUAN}

Karyawan merupakan individu yang terdaftar resmi dan bertugas melakukan pekerjaan yang ada sesuai dengan prosedur yang berlaku, guna mencapai tujuan perusahaan. Perilaku kerja yang positif sangat diperlukan karyawan agar dapat membantu mencapai tujuan perusahaan. Dukungan organisasi tentunya turut berkontribusi dalam munculnya perilaku kerja yang positif maupun yang negatif, dan tentunya perusahaan menghimbau agar terus memunculkan perilaku kerja yang positif, bukan sebaliknya. Menurut Eisenberger dalam Paille, Bourdeau, \& Galois (2010) mengatakan bahwa dukungan organisasi yang dirasakan merupakan persepsi karyawan terhadap bagaimana organisasi menghargai kontribusi mereka dan peduli terhadap kesejahteraan mereka. Salah satu aspek yang terkait disini dijelaskan oleh Sigit (2003,) yakni Attribution (membuat atribusi). Atribusi mengacu pada bagaimana orang menjelaskan penyebab perilaku orang lain atau dirinya sendiri. Ada dua jenis atribusi yaitu atribusi disposisional, yang menganggap perilaku seseorang berasal dari faktor internal seperti ciri kepribadian, motivasi, atau kemampuan, dan atribusi situasional yang menghubungkan perilaku seseorang dengan faktor eksternal seperti peralatan atau pengaruh sosial dari orang lain.

Menurut Baran, et al (2002), peran dukungan organisasi dalam mempengaruhi perilaku karyawan dapat dipahami dengan 3 (tiga) proses. Pertama, berdasarkan norma timbal balik, hubungan antara organisasi dan karyawan seharusnya hubungan timbal balik. Ketika sebuah organisasi menampilkan dukungan tinggi, maka karyawan merasa berkewajiban untuk mengembalikan kebaikan tersebut dengan menunjukkan sikap dan perilaku positif. Sebaliknya, 
ketika dukungan organisasi terlihat rendah, karyawan cenderung bergantian dalam bentuk sikap dan perilaku negatif. Kedua, dukungan organisasi memenuhi kebutuhan sosio-emosional karyawan seperti kebutuhan untuk penghargaan, persetujuan, dan afiliasi yang mengarah pada keterikatan pada organisasi dan pembentukan identitas sosial. Selain itu, pemenuhan aspek sosioemosional juga membantu mengurangi stres di tempat kerja dan meningkatkan kesejahteraan setiap karyawan. Ketiga, dukungan organisasi juga menunjukkan kesiapan organisasi dalam menghargai usaha yang dilakukan oleh para karyawan.

Ketiga proses tersebut, yang telah disebutkan di atas juga didukung oleh penelitian terdahulu. Misalnya, penelitian sebelumnya menemukan bahwa dukungan organisasi meningkatkan rasa merasa berkewajiban, kepercayaan dalam organisasi, keterlibatan kerja, komitmen organisasi, organisasi perilaku kerja kewarganegaraan, dan orientasi tugas (Kurtessis et al., 2015; Karavardar, 2014; Baran et al., 2012; AlKerdawy, 2014).

Selain itu, penelitian yang dilakukan oleh Saira Iqbal Khan et al. (2015), pada karyawan sebuah bank di Pakistan memberikan kesimpulan bahwa dukungan organisasi memiliki pengaruh untuk memunculkan perilaku kontraproduktif.

Berdasarkan latar belakang di atas, Peneliti tertarik untuk meneliti bagaimana gambaran dukungan organisasi yang dirasakan oleh karyawan di PT. XYZ, sekaligus ingin memberikan masukan terhadap perusahaan agar dapat menyusun strategi yang lebih tepat dalam melakukan pengembangan langkah-langkah dalam rangka meningkatkan perilaku positif sekaligus kesejahteraan karyawan yang lebih baik.

\section{Teori}

Dukungan organisasi merupakan persepsi karyawan terhadap bagaimana organisasi menghargai kontribusi mereka dan peduli terhadap kesejahteraan mereka (Eisenberger) dalam Paille, Bourdeau, dan Galois (2010). Hal ini menunjukkan bahwa komitmen dari organisasi kepada karyawannya dapat sangat bermanfaat. Dukungan organisasi menunjukkan perlakuan yang baik dari organisasi menciptakan kewajiban umum, berdasarkan norma timbal balik dari karyawan untuk peduli terhadap organisasi mereka dan memperlakukan organisasi mereka dengan baik sebagai pengembaliannya (Eisenberger et al) dikutip oleh Ristig (2009). Kewajiban karyawan akan dibalaskan melalui perilaku terkait pekerjaan yang akan mendukung berbagai tujuan dari organisasi (Eisenberger et al) dikutip oleh Ristig (2009).

Menurut Robbins (2008) dukungan organisasi yang dirasakaan adalah tingkat dimana karyawan yakin organisasi menghargai kontribusi mereka dan peduli dengan kesejahteraan mereka. Dukungan organisasi dapat juga dipandang sebagai komitmen organisasi pada karyawan. Apabila pihak organisasi secara umum menghargai dedikasi dan loyalitas karyawan sebagai bentuk komitmen karyawan terhadap organisasi, maka para karyawan secara umum juga memperhatikan bagaimana komitmen yang dimiliki organisasi terhadap mereka.

Penghargaan yang diberikan oleh organisasi dapat dianggap memberikan keuntungan bagi karyawan, seperti adanya perasaan diterima dan diakui, memperoleh gaji dan promosi, mendapatkan berbagai akses informasi, serta beberapa bentuk bantuan lain yang dibutuhkan karyawan untuk dapat menjalankan pekerjaannya secara efektif. Terdapatnya norma timbal balik ini menyebabkan karyawan dan organisasi harus saling memperhatikan beberapa tujuan yang ada dalam hubungan kerja tersebut (Rhoades dan Eisenberger dalam Fatdina 2009). 


\section{METODE PENELITIAN}

Metode dari penelitian ini adalah penelitian kuantitatif. Karakteristik responden dalam penelitian ini adalah karyawan PT XYZ, baik laki-laki maupun perempuan, dengan masa kerja minimal 1 tahun dan berasal dari berbagai departemen. Jumlah responden yang diambil sebanyak 153 orang dari populasi yang ada. Teknik sampling yang digunakan dalam penelitian ini adalah purposive (non probability sampling). Variabel dalam penelitian ini adalah dukungan organisasi yang dirasakan. Data didapatkan dengan menyebarkan kuesioner penelitian kepada karyawan yang bekerja di PT XYZ.

Kuesioner penelitian yang digunakan adalah Survey of perceived organizational support yang dibuat oleh Eisenberger, Huntington, Hutchison dan Sowa (1986). Tes survey ini memiliki nilai reliabilitas yang cukup baik ( $r=0.866$ ) untuk digunakan sebagai alat ukur. Contoh item yang digunakan yakni perusahaan akan berusaha keras untuk membantu saya memaksimalkan kemampuan yang saya miliki agar saya dapat menunjukkan kinerja yang terbaik, perusahaan memberikan bantuan ketika saya menghadapi masalah.

Berikut gambaran responden dari penelitian yang dilakukan.

Tabel 1. Gambaran Responden Penelitian

\begin{tabular}{|c|c|c|c|}
\hline \multicolumn{2}{|c|}{ Aspek } & \multirow{2}{*}{$\begin{array}{c}\text { Jumlah } \\
67\end{array}$} & \multirow{2}{*}{$\begin{array}{c}\text { Persentase } \\
43.79 \%\end{array}$} \\
\hline Jenis Kelamin & Laki - Laki & & \\
\hline & Perempuan & 86 & $56.21 \%$ \\
\hline & Total & 153 & $100 \%$ \\
\hline \multirow[t]{3}{*}{ Usia } & $19-25$ tahun & 139 & $90.85 \%$ \\
\hline & $>25$ tahun & 14 & $9.15 \%$ \\
\hline & Total & 153 & $100 \%$ \\
\hline \multirow[t]{4}{*}{ Lama Kerja } & 1 tahun & 60 & $39.22 \%$ \\
\hline & $1-2$ tahun & 77 & $50.33 \%$ \\
\hline & $>2$ tahun & 16 & $10.46 \%$ \\
\hline & Total & 153 & $100 \%$ \\
\hline
\end{tabular}

\section{HASIL DAN PEMBAHASAN}

Untuk mengetahui gambaran dukungan organisasi karyawan di PT XYZ, peneliti melakukan pembagian ke dalam 4 kategori, berdasarkan mean dari item alat ukur yang digunakan, sebagai berikut : $1-2=$ kurang, $2-3=$ rata-rata, $3-4=$ tinggi, $4-5=$ sangat tinggi. Merujuk pada pembagian kategori tersebut, gambaran dukungan organisasi PT. XYZ sebagian besar terletak di kategori 3 yakni tinggi. Hal ini memberikan gambaran bahwa karyawan merasa bahwa perusahaan memberikan dukungan dengan menghargai kontribusi yang telah dilakukan. 
Perusahan juga mampu memaafkan kesalahan yang tidak sengaja dilakukan oleh karyawannya. Perusahaan selalu berusaha untuk membuat kondisi yang senyaman mungkin agar karyawan dapat menyelesaikan pekerjaannya dengan baik. Selain itu, perusahaan juga memberikan pekerjaan sesuai dengan kondisi atau kemampuan karyawan. Beberapa hal tersebut termasuk dukungan perusahaan layak untuk dipertahankan, sehingga terus menunjang kinerja karyawan. Pada kategori 4 yakni sangat tinggi, menunjukkan bahwa dukungan perusahaan yang sangat perlu untuk dipertahankan atau perlu dikembangkan lagi. Hal ini digambarkan antara lain dengan perusahaan mampu memberikan ijin untuk tidak hadir bekerja, jika memang alasannya wajar. Selain itu, perusahaan bersedia memberikan berbagai dukungan agar karyawan dapat menjalankan tugas sebaik mungkin. Sedangkan pada kategori 2, yakni rata-rata, menunjukkan bahwa dukungan perusahaan masih perlu dievaluasi sehingga dapat lebih dirasakan oleh karyawan. Sebagai gambarannya, perusahaan masih harus menemukan cara yang lebih efisien, sebelum memutuskan untuk mengganti seorang karyawan di bagian tertentu. Perusahaan juga harus memiliki alasan yang tepat, saat memberikan pertimbangan pada karyawan untuk tetap bekerja di perusahaan.

Peneliti juga melakukan analisa tambahan terhadap beberapa kriteria yang dikumpulkan. Hasil analisis tambahan diperoleh dari hasil analisis uji beda dukungan organisasi terhadap beberapa aspek.

Tabel 2. Tabel Uji Beda Dukungan Organisasi Berdasarkan Usia Karyawan

\begin{tabular}{lcccccc}
\hline \multicolumn{2}{c}{ Usia (tahun) } & $\mathrm{N}$ & Mean & $\begin{array}{c}\text { Std. } \\
\text { Deviation }\end{array}$ & $\mathrm{F}$ & Sig. \\
\hline Dukungan & $18-25$ & 139 & 3.4763 & 0.34203 & 2.837 & 0.094 \\
Organisasi & $>25$ & 14 & 3.6226 & 0.47973 & & \\
\hline Total & 153 & & & & \\
\hline
\end{tabular}

Dari tabel di atas, tampak rentang usia $18-25$ memiliki rerata lebih rendah

(Mean=3.4763) daripada usia lebih dari 25 tahun (Mean=3.6226), meski secara jumlah karyawannya lebih banyak. Sedangkan hasil analisis uji beda tampak signifikan, yakni $\mathrm{r}=$ 0.094, dengan $\mathrm{p}<0.05$. Hal ini menunjukkan bahwa tidak ada perbedaan dukungan organisasi yang dirasakan, baik pada karyawan yang berusia 18-25 tahun, maupun pada karyawan yang berusia lebih dari 25 tahun.

Tabel 3. Tabel Uji Beda Dukungan Organisasi Berdasarkan Jenis Kelamin Karyawan

\begin{tabular}{lcccccc}
\hline \multicolumn{2}{c}{ Jenis Kelamin } & N & Mean & $\begin{array}{c}\text { Std. } \\
\text { Deviation }\end{array}$ & F & Sig. \\
\hline Dukungan & Perempuan & 67 & 3.5212 & .40492 & 3.333 & 0.070 \\
Organisasi & Laki-laki & 86 & 3.4651 & .31562 & & \\
\hline Total & & 153 & & & & \\
\hline
\end{tabular}

Dari tabel di atas, tampak jenis kelamin laki-laki memiliki rerata lebih rendah $(\mathrm{Mean}=3.4651)$ daripada jenis kelamin perempuan (Mean= 3.5212), meski secara jumlah karyawan laki-laki lebih banyak. Sedangkan hasil analisis uji beda tampak signifikan, yakni $r=0.070$, dengan $p<$ 
0.05. Hal ini menunjukkan bahwa tidak ada perbedaan dukungan organisasi yang dirasakan, baik pada karyawan perempuan maupun karyawan laki-laki.

Tabel 4. Tabel Uji Beda Dukungan Organisasi Berdasarkan Lama Kerja Karyawan

\begin{tabular}{ccccccc}
\hline & $\begin{array}{c}\text { Lama Kerja } \\
\text { (tahun) }\end{array}$ & $\mathrm{N}$ & Mean & $\begin{array}{c}\text { Std. } \\
\text { Deviation }\end{array}$ & $\mathrm{F}$ & Sig. \\
\hline Dukungan & 1 & 60 & 3.4307 & .39521 & 1.401 & 0.249 \\
Organisasi & $1-2$ & 77 & 3.5331 & .33048 & & \\
& $>2$ & 16 & 3.5013 & .32002 & & \\
\hline & Total & 153 & & & & \\
\hline
\end{tabular}

Dari tabel di atas, tampak karyawan dengan masa kerja 1-2 tahun memiliki rerata paling tinggi (Mean=3.5331) dibandingkan dengan karyawan dengan masa kerja 1 tahun (Mean= 3.4307) dan karyawan dengan masa kerja lebih dari 2 tahun (Mean=3.5013). Sedangkan hasil analisis uji beda tampak signifikan, yakni $r=0.249$, dengan $p<0.05$. Hal ini menunjukkan bahwa ada perbedaaan dukungan organisasi yang dirasakan antara karyawan dengan masa kerja 1 tahun, $1-2$ tahun dan lebih dari 2 tahun.

\section{KESIMPULAN DAN SARAN}

\section{Kesimpulan}

Berdasarkan hasil pengolahan data dan analisa pembahasan mengenai dukungan organisasi, dapat diambil kesimpulan yakni dari 153 karyawan yang menjadi responden penelitian:

Sebagian besar terletak di kategori 3 yakni tinggi. Hal ini memberikan gambaran bahwa karyawan merasa bahwa perusahaan memberikan dukungan dengan menghargai kontribusi yang telah dilakukan. Perusahan juga mampu memaafkan kesalahan yang tidak sengaja dilakukan oleh karyawannya. Perusahaan selalu berusaha untuk membuat kondisi yang senyaman mungkin agar karyawan dapat menyelesaikan pekerjaannya dengan baik. Selain itu, perusahaan juga memberikan pekerjaan sesuai dengan kondisi atau kemampuan karyawan. Beberapa hal tersebut termasuk dukungan perusahaan layak untuk dipertahankan, sehingga terus menunjang kinerja karyawan.

Bahwa ada perbedaaan dukungan organisasi yang dirasakan antara karyawan dengan masa kerja 1 tahun, $1-2$ tahun dan lebih dari 2 tahun. Hal ini berarti bahwa karyawan semakin mampu merasakan dukungan perusahaan terhadap kontribusi yang telah karyawan berikan.

\section{Saran}

Gambaran dukungan organisasi yang diperoleh ini dapat menjadi pertimbangan bagi perusahaan PT. XYZ untuk melakukan pengembangan langkah-langkah dalam rangka meningkatkan munculnya perilaku positif sekaligus kesejahteraan karyawan yang lebih baik. 


\section{Ucapan Terima Kasih (Acknowledgement)}

Peneliti menyampaikan ucapan terima kasih kepada pihak manajemen PT. XYZ yang telah berkenan memberikan kesempatan untuk melakukan penelitian. Selain itu, Peneliti juga mengucapkan terima kasih kepada program studi yang telah memberikan bekal untuk menulis dan menyelesaikan penelitian ini, dan rekan-rekan mahasiswa yang saling memberikan dukungan untuk menyelesaikan penelitian ini.

\section{REFERENSI}

AlKerdawy, M. M. A. (2014). The mediating effects of duty orientation on the relationship between perceived organizational support and organizational citizenship behavior in the public banks of Egypt. International Journal of Business and Management, 9(8), 155169. http://dx.doi.org/10.5539/ijbm.v9n8p155

Baran, B. E., Shanock, L. R., \& Miller, L. R. (2012). Advancing organizational support heory into the twenty-first century world of work. Journal of Business and Psychology, 27, 123-147. http://dx.doi.org/10.1007/s10869-011-9236-3

Eisenberger, R., Huntington, R., Hutchison, S., \& Sowa, D. (1986). Perceived organizational support. Journal of Applied Psychology, 71(3), 500-507. http://dx.doi.org/10.1037//00219010.71.3.500

Fatdina. (2009). Peran dukungan organisasi yang irasakan karyawan sebagai mediator pengaruh keadilan prosedural terhadap perilaku kewarganegaraan organisasi. Jurnal Psikologi, $36(1), 1-17$.

Karavardar, G. (2014). Perceived organizational support, psychological empowerment, organizational citizenship behavior, job performance and job embeddedness: A research on the fast food industry in Istanbul, Turkey. International Journal of Business and Management, 9(4), 131-139. http://dx.doi.org/10.5539/ijbm.v9n4p131.

Khan Iqbal Saira, Mahmood Atif, Kanwal Sara, Latif Yasir. (2015). How perceived supervisor support effects workplace deviance? mediating role of perceived organizational support. Pakistan Journal of Commerce and Social Sciences, 2015, 9 (3), 940-967.

Kurtessis, J. N., Eisenberger, R., Ford, M. T., Buffardi, L. C., Stewart, K. A., \& Adis, C. S. (2015). Perceived organizational support: A meta-analytic evaluation of organizational support theory. Journal of Management, 20(10), 1-31. http://dx.doi.org/10.1177/0149206315575554

Kusmarjanti, U., \& Soetjipto, H. P. (2007). Dukungan organisasi dan komitmen organisasi. Jurnal Kebijakan Dan Administrasi Publik, 11, 27-41.

Paille, Pascal., Bourdeau, Laurent., \& Galois, Isabelle. (2010). Support, trust, satisfaction, intent to leave and citizenship at organizational level: a Social exchange approach. International Journal of Organizational Analysis. 18(1): 41-58.

Ristig, K. (2009). The impact of perceived organizational support and trustworthiness on trust. Management Research News. 32(7): 659-669.

Robinns, S. P., Timothy A. J. (2008). Perilaku Organisasi Buku 1 Edisi 12. Salemba Empat, Jakarta.

Sigit, S. (2003). Esensi Perilaku Organisasi. Yogyakarta: BPFE Universitas Sarjanawiyata Tamansiswa. 